\title{
¿Y el derecho al ambiente qué? Representaciones y prácticas locales en asentamientos informales, enmarcados en la causa judicial de saneamiento de la cuenca Matanza Riachuelo, en el Área Metropolitana de Buenos Aires
}

¿And What About the Environment? Local Social Representations and Practices in Informal Settlements Framed in the Court Case for the Sanitation of the Matanza Riachuelo Basin in the Metropolitan Area of Buenos Aires E o direito ao meio ambiente? Representações e práticas locais em assentamentos informais enquadrados na causa judicial de saneamento da bacia Matanza Riachuelo, na área metropolitana de Buenos Aires

\section{Carla Fainstein ${ }^{*}$}

Recibido: 20 de noviembre de 2020

Aprobado: 25 de marzo de 2021

https://doi.org/10.12804/revistas.urosario.edu.co/territorios/a.9920

Para citar este artículo

Fainstein, C. (2021). ¿łY el derecho al ambiente qué? Representaciones y prácticas locales en asentamientos informales, enmarcados en la causa judicial de saneamiento de la cuenca Matanza Riachuelo, en el Área Metropolitana de Buenos Aires. Territorios (45), pp. 17-39. https://doi.org/10.12804/revistas.urosario.

* FLACSO - Sede Argentina / CONICET. Correo electrónico: carla.fainstein@gmail.com. ORCID: https://orcid.org/00000002-6504-0586 
Palabras clave

Asentamientos informales; conflictos ambientales; judicialización;

representaciones sociales; organización social; políticas públicas.

Keywords Informal settlements; urban environmental conflicts; judicialization; social representations; social organizations; public policies.

Palavras-chave Assentamentos informais; conflitos ambientais;

judicialização; representações sociais; organização social; políticas públicas.

territarias 45

\section{RESUMEN}

El presente trabajo se propone indagar sobre lo que sucede luego de la sentencia de una causa estructural, centrada en el derecho al ambiente en un territorio urbano. Se tomará el caso de la judicialización del saneamiento de la cuenca Matanza Riachuelo, una de las zonas más contaminadas de la Argentina, que atraviesa el Área Metropolitana Buenos Aires. El fallo supuso el despliegue de una batería de políticas, entre ellas la urbanización y relocalización de asentamientos informales localizados en la cuenca. se indagará en torno a las representaciones de los habitantes de estos barrios, sobre su ambiente y sus derechos en general. Además, se analizarán el accionar estatal y las tradiciones de los movimientos villeros en la zona, como elementos a considerar para examinar las características las características de estas percepciones. Se utilizó una metodología cualitativa realizando trabajo de campo en dos asentamientos de la cuenca entre los años 2014 y 2018.

\section{ABSTRACT}

The present exposition aims to investigate what happens after the sentence of a structural case centered on the right to the environment in an urban territory. We will take the case of the judicialization of the sanitation of the Matanza Riachuelo basin, one of the most polluted areas of Argentina, which runs through the Buenos Aires Metropolitan Area. The ruling involved the deployment of a battery of policies, including the urbanization and relocation of informal settlements located in the basin. In this work we will investigate the representations of the inhabitants of these neighborhoods about their environment and their rights in general. In addition, the state actions and the traditions of the villeros movements in the area will be analyzed as elements to consider to investigate the characteristics of these perceptions. A qualitative methodology was used, carrying out field work in two settlements in the basin between 2014 and 2018 .

\section{RESUMO}

O presente trabalho tem como objetivo investigar o que ocorre após a sentença de um caso estrutural centrado no direito ao meio ambiente em um território urbano. Tomaremos o caso da judicialização do saneamento da bacia da Matanza Riachuelo, uma das áreas mais poluídas da Argentina, que atravessa a área metropolitana de Buenos Aires. A decisão envolveu a implantação de uma bateria de políticas, entre elas a urbanização e realocação de assentamentos informais localizados na bacia. Neste trabalho, iremos investigar as representações dos moradores desses bairros sobre seu ambiente e seus direitos em geral. Além disso, serão analisadas as ações do Estado e as tradições dos movimentos dos moradores dessa zona, como elementos a serem considerados para investigar as características dessas percepções. Foi utilizada uma metodologia qualitativa, realizando trabalhos de campo em dois assentamentos da bacia, entre os anos de 2014 e 2018. 


\section{Introducción}

La cuenca Matanza Riachuelo atraviesa el Área Metropolitana de Buenos Aires y constituye uno de los territorios más contaminados de la Argentina, por lo que, históricamente, ha sido objeto de diversas políticas ambientales, en su mayoría infructuosas. Estos problemas ambientales fueron judicializados y llegaron hasta el máximo organismo de la justicia argentina, que dictó sentencia sobre esta causa en el año 2008, ordenando el saneamiento del territorio y la mejora de las condiciones de vida de su población. La llamada causa "Mendoza" y su sentencia fueron estructuradas por el Poder Judicial en torno al eje ambiental. Este derecho era el que la fundamentaba, basándose en una novedosa legislación nacional y fundada en tratados internacionales, como coronación de un proceso de creciente visibilización y puesta en la agenda pública y política de los conflictos ambientales en América Latina y en la Argentina en particular (Merlinsky, 2013; Bergallo, 2014).

Existe una prolífica bibliografía sobre la causa, las problemáticas ambientales de este territorio y las políticas urbano ambientales diseñadas e implementadas a partir de la sentencia por lo significativas que fueron en términos de política ambiental y por los conflictos suscitados en estos procesos. Sin embargo, encontramos una vacancia en lo que refiere a las perspectivas de los habitantes de este territorio sobre su ambiente, la causa judicial y las políticas implementadas a raíz de ella. Como han afirmado Auyero \& Swistun (2007), existen escasas investigaciones que pongan el foco en la dimensión ambiental de la pobreza urbana y en el sufrimiento ambiental como una expresión de la desigualdad.

El objetivo de este artículo es indagar en las representaciones sociales sobre el ambiente de los sectores populares urbanos y, en particular, en grupos que se encuentran afectados por una causa judicial y una serie de políticas públicas con un discurso fuertemente ligado a la garantía de su derecho al ambiente. El análisis aborda la reinterpretación, aprendizajes y utilización estratégica del discurso ambiental por parte de organizaciones de asentamientos informales en su vinculación con actores estatales. A su vez, analiza cómo las acciones de estos últimos inciden en el proceso aludido.

Interesa, por tanto, indagar sobre lo que sucede luego de las sentencias judiciales en la territorialización (Melé, 2007) de las políticas que ordenó el fallo y sobre los múltiples conflictos que se desencadenaron a partir de ellas. Muchos eran preexistentes y se reordenaron en esta nueva arena de disputa (Smulovitz, 2008) y otros nacieron en este nuevo marco. Los conflictos fueron de tipo urbanoambiental, por tratarse de aquellos conflictos sociales en los que al menos una de las partes hace valer un argumento ambiental; pero eso no será un obstáculo para reconocer las otras dimensiones 
del conflicto. En particular, se trata de "tomar en serio" la importancia tanto de las motivaciones de los actores "no ambientalistas", como las condiciones o motivaciones no ambientales de quienes enarbolan las causas ambientales (Azuela \& Mussetta, 2009, p. 3).

Se articularán estas perspectivas con análisis en los campos de la sociología y la antropología política. En particular, los trabajos que han abordado la relevancia de la regulación estatal en la conformación y desarrollo de organizaciones sociales territoriales (Moreno, 2013), así como el uso estratégico por su parte del lenguaje estatal para hacer valer sus demandas (Olejarczyk, 2017; Manzano, 2008). Por otra parte, se integra la bibliografía que ha puesto el foco en la creciente incorporación del lenguaje de derechos y su aprendizaje en las organizaciones sociales (Ferraudi Curto, 2014; Smulovitz, 2008; Delamata et al., 2014) como marcos de significación de su acción colectiva (Snow, 2004) así como el empleo de este y del enfoque de derechos en la política pública (Arcidiácono \& Gamallo, 2013).

El artículo pone en diálogo los campos de los estudios ambientales, urbanos y políticos, mostrando la incidencia de la política estatal en la conformación de organizaciones de base territorial y en la manera en que se formulan sus demandas, en este caso, en términos de derecho al ambiente. Esto constituye una utilización estratégica del lenguaje del Estado como forma de legitimación y de establecer negociaciones por parte de los referentes, a la vez que coexiste con las tradiciones históricas de estos movimientos en la Argentina, más ligados a las reivindicaciones por el acceso a la tierra y la vivienda. Este proceso se desarrolla en un marco en el que las prácticas estatales reproducen la incertidumbre y la confusión de los "beneficiarios" del saneamiento de la cuenca hídrica en relación a la contaminación ambiental y las políticas que buscan abordarla. En este marco, los habitantes de la cuenca conviven con este entorno tóxico articulando esta información confusa con sus propias experiencias cotidianas con su ambiente.

Retomaré en este escrito algunos de los resultados obtenidos en la investigación realizada en mi tesis doctoral, para la que llevé adelante una estrategia metodológica cualitativa, en la que triangulé diversos instrumentos y fuentes de datos. El corpus principal estuvo compuesto por entrevistas en profundidad a los miembros de las organizaciones de dos barrios de la cuenca, la villa 21-24 de Barracas (ubicada en la ciudad de Buenos Aires), se entrevistaron las personas que conformaron el Cuerpo de Delegados del “camino de sirga" (sector afectado por la sentencia judicial) y los referentes del Campo Unamuno (Partido de Lomas de Zamora, en el Conurbano Bonaerense), un conjunto de asentamientos informales organizados en una Mesa Barrial conformada por referentes de cada uno de sus sectores. Además, se entrevistaron a 
funcionarios públicos y miembros de ONG involucrados con la causa y a habitantes de otros barrios de este territorio. Por último, se trabajó también con diversos documentos judiciales, del Poder Ejecutivo y de otros organismos. El trabajo de campo se realizó entre 2014 y 2018.

El artículo se divide en cinco apartados. En primer lugar, se describirá brevemente el territorio de la cuenca y la causa judicial que dictaminó su saneamiento para contextualizar el análisis. Luego, se indagará en algunas características del accionar del Poder Ejecutivo en estos territorios. En tercer lugar, se considerarán las representaciones sociales de los habitantes de asentamientos informales sobre su ambiente y, por último, se ahondará en el aprendizaje de derechos como un efecto de estos conflictos ambientales y en la utilización estratégica del discurso ambiental por parte de las organizaciones de los barrios de la cuenca. Finalmente, se presentarán algunas reflexiones preliminares.

\section{El río desechado: la judicialización de la contaminación urbana}

Yo digo, si en Europa pudieron arreglar el Támesis, si los japoneses pudieron arreglar su rio, ¿por qué carajo nosotros queremos que se muera? Supongo que, porque el Támesis corre por el centro de Londres, este no corre por el centro de Buenos Aires, corre por el costado donde están los negros ... Esa es la verdad (Antonio, 2018)
La cuenca del río Matanza Riachuelo (ver figura 1) atraviesa el Área Metropolitana de Buenos Aires (AMBA) desde el sudoeste hasta desembocar en el Río de La Plata, constituyendo en su último tramo el límite entre la ciudad de Buenos Aires y los municipios del Conurbano Bonaerense, parte de la Provincia de Buenos Aires. Es uno de los territorios más contaminados del país, principalmente por ser una zona de alta concentración de industrias (destacándose graserías, curtiembres, herrerías, astilleros y frigoríficos), mayores agentes contaminantes del suelo, aire y agua de este territorio (Merlinsky, 2014).

En la cuenca encontramos también un alto número de basurales a cielo abierto y graves déficits en las redes de desagüe de los barrios aledaños, que vierten parte de sus residuos al río. Además, la cuenca alta constituye un área rural (así como parte de la cuenca media) con un uso intensivo de agrotóxicos, siendo todos estos factores los que agravan el deterioro ambiental de la zona (Gutiérrez, 2012).

Habitan este territorio casi nueve millones de personas (según cálculos de la Autoridad de Cuenca Matanza Riachuelo del año 2014). Se observa una fuerte injusticia ambiental, ya que las áreas más degradadas ambientalmente son habitadas por los sectores más vulnerables. ${ }^{1} \mathrm{La}$ cuenca presenta una sobreocupación de las costas por numerosas villas y asentamientos informales (Merlinsky, 2013). Se calcula que alrededor de 1.716.029 personas - es decir, el 32,3\% de la población
Para el año 2009, la Autoridad de Cuenca Matanza Riachuelo (ACUMAR) calculaba que un $30 \%$ de las viviendas en ese territorio no tenía conexión a redes de agua y que el $55 \%$ no tenía acceso al servicio de cloacas. territarias 45

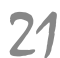


${ }^{2}$ Llamaremos a la causa de esta manera de ahora en más.
Figura 1. Fundación Ciudad, 2004

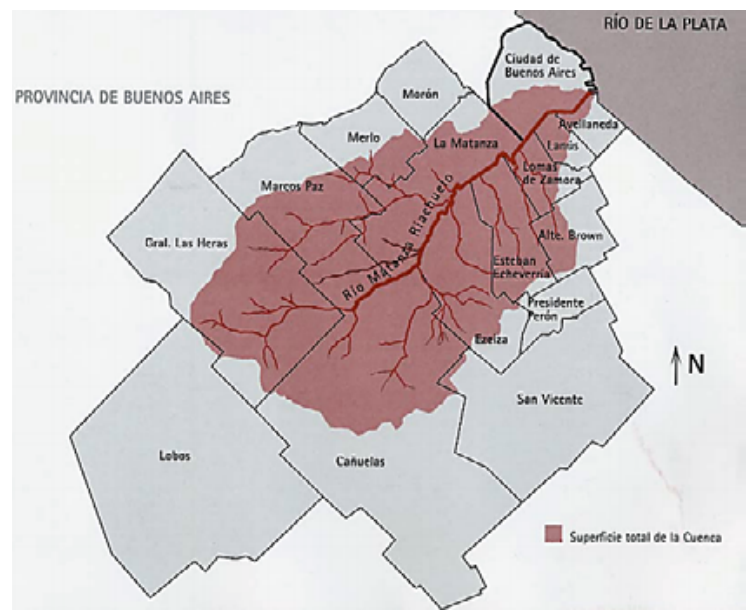

Fuente: Observatorio Metropolitano de la CPAU.

total - habitan en villas y asentamientos en este territorio, mientras que el porcentaje para el total del AMBA, en el año 2006, era del 11,51\% (Cravino et al., 2008).

En el año 2004, un grupo de vecinos de uno de los municipios atravesados por la cuenca presentó una demanda contra el Estado Nacional, la Provincia de Buenos Aires, el Gobierno de la Ciudad de
Buenos Aires y 44 empresas ubicadas en la cuenca por daños y perjuicios sufridos como consecuencia de la contaminación del río Matanza-Riachuelo (ver figura 2). En un contexto de gran presencia de los conflictos ambientales en la agenda pública en el país, la Corte Suprema de Justicia de la Argentina declaró su competencia en la causa en el año 2006 y dictó sentencia en el 2008, convirtiendo a la causa 
"Mendoza"2 y su fallo en un hecho histórico en términos de derecho ambiental. El Supremo Tribunal ordenó el saneamiento integral de la cuenca, la prevención de daños futuros y la mejora de las condiciones de vida de su población. Había ordenado ya en el año 2006 la creación de la Autoridad de Cuenca Matanza Riachuelo (ACUMAR), organismo interjurisdiccional novedoso en la administración pública argentina. También dictaminó que los actores del Poder Ejecutivo demandados debían elaborar un plan que abordara los tres objetivos marcados en el fallo, por lo que en el año 2010 fue aprobado el Plan Integral de Saneamiento Ambiental de la Cuenca Matanza Riachuelo (PISA).
El PISA tuvo más de diez líneas de acción que abordaron la complejidad de la problemática ambiental de la cuenca. Entre ellas encontramos las de "contaminación de origen industrial", "saneamiento de basurales", "ordenamiento ambiental del territorio", "liberación de márgenes y camino de sirga", "urbanización de villas y asentamientos precarios" y "expansión de la red de agua potable y saneamiento cloacal". Una parte importante de las acciones delineadas en el plan (en particular las nombradas) tenían por objeto los asentamientos informales localizados en la cuenca y sus habitantes y, en especial, aquellos radicados en la ribera a lo largo del río. Las políticas vinculadas a

Figura 2. Ribera de la Villa 21-24 de Barracas en la ciudad de Buenos Aires

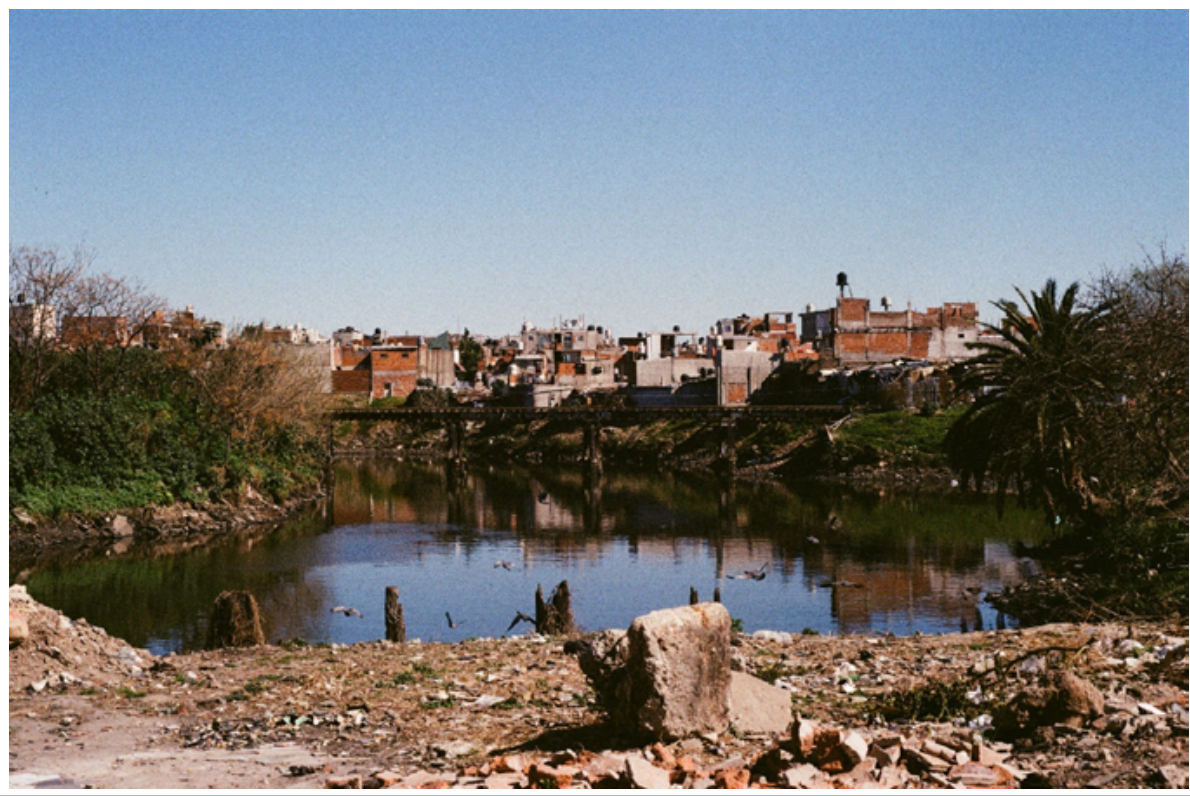

Fuente: tomado de Fainstein, 2015. 
este último punto cobraron particular peso y relevancia pública porque implicaron la relocalización de centenas de familias, procesos (incompletos) que en muchos casos se ejecutaron de manera violenta y poco participativa, generando múltiples y complejos conflictos (Cravino \& Fainstein, 2017). En cada distrito la implementación de estas políticas tuvo diversos alcances y consecuencias vinculadas con las características de los gobiernos municipales (principales responsables de ejecutar estas acciones), pero también de las organizaciones y características propias de cada uno de los asentamientos. Además, el proceso estuvo atravesado por la ausencia total de espacios de participación para los habitantes de la cuenca en el ámbito legal.

Comenzó así un proceso de implementación de políticas de manera interjurisdiccional e integral que lleva ya más de diez años y que ha presentado muchas dificultades y obstáculos en su implementación. Nos ocupa en este trabajo abordar la esfera de las representaciones sociales y prácticas de los habitantes de la cuenca, más que realizar un balance de las acciones ejecutadas. Estas se vinculan tanto con las tradiciones organizativas del movimiento villero argentino como con el accionar -previo y en el marco de este litigio- del Poder Ejecutivo y Judicial en estos territorios. El objetivo es entonces entender qué sucede en la territorialización (Melé, 2003) de un fallo estructural y la batería de políticas públicas que conlleva, entendiendo que se encontrará con un conjunto de actores barriales con sus propias demandas y agendas políticas que no necesariamente se articulan fácilmente.

Los barrios que se consideran como casos de estudio fueron objeto de estas acciones estatales, aunque los diseños e implementaciones de los proyectos fueron diferentes. A pesar de que para ambos regía la línea de acción de urbanización y relocalización de villas, en el caso de la villa 21-24 de Barracas la acción pública se centró en la reubicación de la población que habitaba en la ribera a conjuntos habitacionales. No se han realizado intervenciones en el resto del barrio a partir de este litigio judicial. Se conformó en el sector del "camino de sirga" una organización ad hoc que representó frente a los distintos actores estatales los intereses de los vecinos que debían mudarse. Los delegados tenían recorridos muy variados, desde personas con una profunda participación en la vida política del barrio hasta otras que atravesaron con esta experiencia su primer acercamiento a espacios de organización colectiva. En el caso del Campo Unamuno, le correspondían también acciones de urbanización y relocalización (pero relacionadas con la apertura de calles y el esponjamiento del barrio para su urbanización), las cuales han avanzado con extrema lentitud y deficiencia a lo largo de estos años (ver para un análisis de mayor complejidad Fainstein, 2019). Los distintos barrios 
que componen el Campo Unamuno se organizaron en una instancia común, de la que participaban referentes con extensas y variadas trayectorias políticas.

\section{La producción social de confusión sobre el ambiente}

\section{E: ¿Y sobre el rio? ¿Sobre el agua hay algún cambio?}

J: Me estás gastando vos, ¿no? (José, 2018)

Como se ha afirmado, el eje principal de la causa "Mendoza" fue la vulneración del derecho al ambiente. Sin embargo, esta no fue la demanda principal de sus habitantes al confrontar o negociar con los actores estatales en la implementación de las políticas del PISA. Esto se debió a diversas cuestiones, y una de ellas es el accionar contradictorio, confuso e incierto de los actores del Poder Ejecutivo y Judicial.

El Estado no llevó adelante acciones concretas en los asentamientos que dieran cuenta, más allá de lo discursivo, de una política sustantiva que pusiera en primer plano la garantía del derecho al ambiente de los pobladores de la cuenca. Esto no quiere decir que no se llevaran adelante obras de este tipo, pero no eran visibles en la cotidianeidad para los vecinos, y el Estado tampoco comunicó la realización de estas obras ni explicó su utilidad con eficacia y claridad. Para los habitantes de los barrios de la cuenca, lo más notable fueron las políticas de relocalización, algunas obras vinculadas con la urbanización y, principalmente, la limpieza de la ribera.

En este sentido, más allá de que el derecho al ambiente no formaba parte de las demandas históricas de estos barrios, la forma de actuar del Estado no hizo más que dejar relegado este derecho en la mirada de los entrevistados, por lo que no sorprende que no haya sido parte central de las demandas de las organizaciones sociales de los asentamientos. Podemos en este sentido observar dos formas del accionar público que pueden haber reforzado el corrimiento de la cuestión ambiental de la agenda de estas organizaciones. Por una parte, la desinformación y confusión permanente transmitida a estas poblaciones acerca del asunto (en especial en lo relacionado con cuestiones de salud) y por el otro, la realización de acciones, que parecieron directamente contraponerse al objetivo de mejorar las condiciones de vida ambientales de los vecinos. Esto tiene como resultado lo que Javier Auyero y Débora Swistun (2007) llamaron la producción social de confusión por parte del Estado, que no es más que una forma de la dominación política de los sectores populares.

Las entrevistas realizadas en ambos barrios dieron cuenta en particular de la preocupación e incertidumbre generada por la falta de seguimiento de los estudios de salud ambiental realizados por el ACUMAR en una primera etapa de las políticas. Según los referentes, desde el 
${ }^{3}$ Ver, por ejemplo, https:// www.youtube.com/ watch? $v=12$ Sn GmtOrcs

${ }^{4}$ Figura del Código Civil argentino que fue utilizada en los documentos judiciales para marcar el ancho que deberian tener los sectores públicos de la ribera del río "liberados de obstáculos" - tales como industrias, basurales $y$ viviendas-.

\section{territarias 45} 26
Poder Ejecutivo nacional se habían realizado estudios - la Evaluación Integral de Salud en Áreas de Riesgo (EISAAR) - que habían dado indicios de que la salud de los habitantes de la cuenca estaba en fuerte riesgo, y luego no se habían continuado los estudios ni seguido los casos que se habían detectado en estas evaluaciones. El dato que más quedó en el imaginario y que fue publicado en diversos medios de comunicación y producciones de las organizaciones barriales fue que el 25\% de los niños de la villa 21-24 de Barracas tenían niveles altos de plomo en sangre debido a la contaminación. ${ }^{3}$ Es lógica entonces la confusión o descreimiento de poblaciones a las cuales les dijeron que las medidas sobre sus barrios (entre ellas mudanzas) eran urgentes, prioritarias, ineludibles, les brindaron información que mostraba una aparente gravedad $y$, luego, en diez años no se observan acciones estructurales tendientes a modificar esas condiciones críticas de vida. Como ya ha marcado Pierre Bourdieu (1999) el manejo del tiempo de los demás es una forma de dominación sobre los sectores subordinados.

Como hemos dicho, a esto se le suma la desinformación, como lo expresaba una de las dirigentes del Campo Unamuno:

Decime qué es la contaminación porque no sé si es la tierra, no sé si es de la fábrica, no sé si es del agua. Nunca se sabe porque como te lo hacen muy químico... Yo perdí a mi hija gracias a toda la contaminación y me dijeron "¿Por qué no le hacés juicio a la fábrica?" Digo, si yo le hago juicio a la fábrica y me la devuelven a mi hija con vida yo le hago. (Nuria, 2018)

En esta cita se sintetiza la combinación entre falta de información precisa y la gravedad de la extensión de los tiempos de espera (Auyero, 2013) en este caso. A esto se sumó, como afirmamos, la realización de acciones, en apariencia contradictorias, con el acceso al derecho al ambiente por parte de los actores estatales. En términos generales, puede destacarse el hecho de que "el camino de sirga"4 no posee ningún fundamento ambiental. Marca que los 35 metros desde la orilla de un río o canal deben ser espacio público, pero no está especificado que se vincule con el riesgo ambiental. Esto plantea al menos tres preguntas: la primera es ¿qué pasa en el metro 36? la segunda ¿̇es igual la contaminación en la cuenca baja, densamente poblada y con una alta concentración de industrias contaminantes, que en la cuenca alta y media? Y la tercera, ¿Sirve utilizar el mismo criterio para toda la cuenca? Estas preguntas no fueron respondidas hasta muchos años después de la sentencia, ya que por los primeros diez años no existió un diagnóstico que definiera la urgencia y gravedad del riesgo ambiental en cada zona. En este sentido, podemos destacar el hecho de que en la villa 21-24 algunos de los complejos de vivienda nueva, para las familias relocalizadas, se encontraban a distancias muy 
similares al Riachuelo a las que habitaban previamente. Así se expresaba al respecto una de las delegadas de ese barrio:

Los que se van se van ahí a la vuelta a Mundo Grúa. Y, por ejemplo, el ambiente ahí también está contaminado ¡Es la misma cosa! Por eso digo, yo nomás digo, es mi opinión personal... estrategia política. ¿Entendés? Que adelante allá del otro arreglaron y ponen el camino así (se refiere al camino que ya está armado frente a Mundo Grúa), pero mientras que no limpien el Riachuelo como se debe, siempre va a estar contaminado el barrio... Porque si ya viene por el ambiente de uno. (Beatriz, 2016)

Otra de las referentes también aludía a la aparente falta de fundamento en criterios ambientales de estas mudanzas:

Yo creo que la mudanza es una mejora para el Estado. El estado de tapar la necesidad que hay, la pobreza que hay. Porque a ver. Me mudan a 35 metros. Me sacan de 35 metros del Riachuelo, me relocalizan a 36 metros. Porque acá [...] O Mundo Grúa también, te van a relocalizar... A ver, 36 metros, a ver, eso es tapar la pobreza. Los mandás de un lugar a otro lugar, y tal vez peor. (María, 2016)

En el Campo Unamuno, por su parte, recuperamos el relato de uno de sus referentes para dar cuenta también de estas contradicciones:
Nos habían entregado un papel, supuestamente de la autoridad de la tierra, y lo que decía era que la tierra estaba libre de contaminación [...] Certifica que está libre de contaminación y vos vas y metés la pala y encontrás tanques con hidrocarburo, viste, es todo un contrasentido. $\mathrm{Y}$ todo porque no habían hecho ni la debida inspección, no habían venido a ver el lugar, simplemente mintieron un certificado, como ellos tienen el sello... No verificaron nada, viste. (Antonio, 2018)

Antonio se refiere a que, al ver las tierras donde se construirían viviendas para las familias del Campo Unamuno, los vecinos encontraron tanques enterrados con contenidos que debieron ser analizados, en el suelo que les habían certificado que estaba libre de contaminación y a donde iban a mudarse justamente por el riesgo ambiental sufrido en sus viviendas.

Como planteamos más arriba, no podemos pensar la formulación de demandas por parte de las organizaciones barriales sin considerar el accionar estatal y las relaciones que con ellos desarrollan en estos procesos (Olejarczyk, 2017). En este caso, ponen en evidencia que las propias acciones públicas, cuyo objetivo último se vinculaba con la mejora de las condiciones de vida ambientales de la población, aparecieron como confusas, inciertas y contradictorias para los referentes, reforzando el hecho preexistente de que el derecho al ambiente no formara parte del marco cultural o framing (Snow, 2004) de sus 
${ }^{5}$ Traducción de la autora.

- Para más lecturas sobre los movimientos por el acceso a la tierra y la vivienda en el Área Metropolitana de Buenos Aires ver Cravino, 1998; Grimberg, 2009; $\mathrm{Na}$ talucci, 2011; Camelli, 2017; Snitcofsky, 2018, entre otros.

\section{territarias 45} 28 acciones colectivas. Estos enmarcamientos son aquellos mecanismos de articulación que atan "los diversos elementos de una escena para que una serie de sentidos antes que otros sean transmitidos o, en el lenguaje de la narrativa, que una historia sea contada en vez de otra" (Snow, 2004, p. 384$).^{5}$

\section{Niebla del Riachuelo: representaciones y demandas por un ambiente sano}

Como han expresado Patrice Melé (2007) y Antonio Azuela de la Cueva y Paula Mussetta (2009), los conflictos son situaciones en las que se revelan las visiones de mundo de los distintos actores. Los suscitados a partir de la implementación de las políticas del PISA nos permiten observar, en las demandas y en las acciones colectivas llevadas adelante por las organizaciones barriales, sus percepciones sobre la vivienda, el hábitat y el ambiente. Cabe complementar esta mirada con aquellas que han reconstruido las trayectorias históricas del movimiento villero en la Argentina, ya que las demandas no se construyen en el vacío sino sobre la memoria colectiva barrial y las experiencias de participación cotidiana que las reproducen y producen.

En principio cabe remarcar que la demanda por la vivienda "digna, permanente y definitiva" y por la urbanización de los barrios primó por sobre aquellas relacionadas al ambiente. Más allá de debatir si estos reclamos podrían ser también parte de una agenda ambiental, no fueron establecidos utilizando esos marcos de significado sino desde el reclamo histórico de los movimientos villeros en la Argentina, la demanda por tierra y vivienda. La vivienda, el hábitat y el acceso al suelo urbano habían constituido históricamente los ejes de las disputas de los movimientos villeros de la ciudad (Camelli, 2011; Cravino, 2008), marcando su memoria colectiva (Halbwachs, 2004) y sus repertorios de acción frente al Estado. En distintos períodos este movimiento (al cual no podemos referirnos como algo homogéneo o incluso unificado) desarrolló diversas formas organizativas y acciones colectivas. Las demandas se fueron transformando (también con los paradigmas de política pública que se fueron desarrollando), pero siguieron motorizándose centralmente por el acceso a la tierra y la vivienda. Desde la década de los noventa estas reivindicaciones se reordenaron también en las de los movimientos de desocupados que, además de tener al trabajo como reclamo central, incorporaron el aspecto del hábitat y desarrollaron además una inscripción territorial que fue fundamental para analizar estos procesos (Merklen, 2010; Svampa, 2003). ${ }^{6}$

Estas luchas se reactualizaron en los conflictos enmarcados en la causa judicial. Las experiencias previas de los actores se articularon fuertemente en estos barrios conformando el fundamento de las acciones de la organización barrial (Fainstein, 
2018). Cabe destacar también que, más allá de la historia barrial compartida, las trayectorias de participación específica de los referentes entrevistados conformaron también una dimensión con un rol relevante en la constitución de los marcos de significación (Snow, 2004) de las acciones colectivas en estos conflictos. Más allá de sus heterogeneidades y matices, cuyo desarrollo excede las posibilidades de este artículo, los delegados poseían largos recorridos de participación en los conflictos y las demandas de sus barrios por el acceso a la tierra y la vivienda. Muchos de ellos habían desarrollado sus experiencias enmarcadas en organizaciones sociales o partidos políticos, mientras que otros lo habían hecho de manera independiente, formando parte de las diversas instancias barriales. También había personas con experiencias previas en la militancia sindical, en movimientos de derechos humanos y en actividades eclesiásticas en sus territorios. Este acervo de conocimientos y experiencias se puso en juego en los conflictos suscitados en la implementación de las políticas públicas judicializadas.

El derecho a la vivienda se demandó refiriéndose a sus aspectos materiales, pero también a los simbólicos. Los reclamos se ordenaron, principalmente, en torno a la calidad constructiva, las características estéticas (Pelli, 2004), el diseño y el acceso a servicios de las nuevas viviendas. Emergió el reclamo por el "derecho al espacio urbano" (Oszlak, 1991), poniendo en un primer plano la posibilidad de elegir la localización de las viviendas. A esto se le sumó, como demanda, el evitar la ruptura con lo que uno de los referentes denominó su "centro de vida", es decir, su espacio barrial. Se referían a su territorio de pertenencia simbólica y cultural central, además, para el desarrollo material y social de sus familias y vecinos (Gravano, 2003). Las demandas por el acceso al título de propiedad del suelo y por la urbanización integral de los asentamientos fueron las que aparecieron con mayor relevancia, como expresó una de las dirigentes barriales del Campo Unamuno, "lo más importante sería que se nos haga la vivienda como corresponde, principalmente que nos den los terrenos" (Julia, 2018). La casa propia apareció como el mayor logro posible a alcanzar, como se relataba en la nota de una revista del barrio: "a todos nos une el mismo deseo [...], el sueño de tener nuestras propias tierras, nuestro propio hogar. Luchamos por la tranquilidad y la seguridad de que nadie nos puede sacar lo que es nuestro" (Fiorito participa, 2013, p. 9). Este horizonte de la movilidad social ascendente, que se había vuelto imposible de obtener por la vía del mercado, era ahora algo plausible gracias a la urbanización (Ferraudi Curto, 2014, p. 166).

\section{¿Y el derecho al ambiente?}

Como afirmamos, las demandas centrales de las organizaciones barriales de territarias 45 
${ }^{7}$ Es importante destacar que la Argentina posee un fuerte activismo ambiental, heterogéneo, federaly con una larga tradición histórica, pero que no se ha desarrollado particularmente en conflictos ambientales que atraviesen el ámbito urbano sino más bien ligado con la matriz extractivista del país (por ejemplo, los movimientos contra la megaminería, la contaminación por agrotóxicos o la deforestación). Para mayores lecturas sobre el tema ver Merlinsky, 2014; Svampa, 2019, entre otros. Queda por indagar en procesos recientes en los que comienza a discutirse, con gran profundidad en la Argentina, la vinculación entre las ciudades y los problemas ambientales.

\section{territarias 45}

la cuenca fueron el acceso a la vivienda propia y la urbanización de sus barrios. Las problemáticas vinculadas al derecho al ambiente y las representaciones sobre el mismo quedaron relegadas porque no jugaron un papel central en los procesos analizados como demandas de los referentes barriales. ${ }^{7}$ Esto nos lleva a plantear que el problema que las políticas del PISA venían a resolver, tal como había sido delimitado por la causa originaria, fue redefinido a partir de la implementación de la sentencia. En ambos asentamientos, los reclamos por la garantía del derecho a la salud y la mejora de los sistemas de recolección de residuos aparecieron con fuerza, pero no enmarcados más ampliamente dentro de la demanda por el derecho al ambiente.

En principio, cabe destacar que las formas de experimentar la contaminación, así como los saberes de estos pobladores acerca de la misma no son homogéneos ni dentro de las organizaciones ni en estos barrios en general (Auyero \& Swistun, 2007; Scharager, 2017). Sí podemos remarcar que, en medio de la confusión e incertidumbre (de la que ya hemos hablado), el estar en contacto por años con actores estatales, que buscaron negociar y exponer sus posiciones enmarcadas en un discurso ambiental, les dio a los referentes de las organizaciones barriales ciertas herramientas técnicas para comprender su vida cotidiana en su relación con el Riachuelo.
A lo largo de las entrevistas realizadas y del extenso trabajo de campo en las asambleas y reuniones del cuerpo de delegados de la villa 21-24, el mismo no formó parte de las preocupaciones y discusiones centrales de este espacio. Aunque la mayoría de los referentes reconocía la existencia de esta problemática, fundamentalmente vinculada a la contaminación del río y los graves problemas de salud que el mismo traía a las familias que habitaban sus orillas, el eje de los debates y las demandas fueron los ya nombrados. Este punto es el que nos interesa indagar con mayor profundidad, al desmenuzar las definiciones que los representantes le adjudican al "derecho al ambiente", que se relacionan con lo que Auyero \& Swistun (2007) denominaron "sentidos de la contaminación" que estaban circulando en el barrio: ¿Por qué en la causa judicial de mayor envergadura - y con un gran impacto en políticas públicas de escala metropolitana, en relación al saneamiento ambiental en el territorio- el problema se redefinió en términos de la garantía para la población villera de los derechos a la vivienda, al hábitat y a la ciudad?

En el trabajo de campo encontramos que la contaminación y el "estar contaminados" se ligaban directamente a la salud de los habitantes de estos barrios. Según la mayoría de los entrevistados, los vecinos tenían noción de las enfermedades que el Riachuelo traía antes de la sentencia de la CSJN - debido a su “experiencia tóxica”: "la contaminación 
se 'detecta' en el propio cuerpo" (Auyero \& Swistun, 2007, p. 204)-, pero esto no lo constituyó de por sí en parte del marco de significados de las organizaciones. En su experiencia cotidiana, los vecinos observaban la presencia de enfermedades respiratorias, dermatológicas y de otros tipos en las personas que habitaban en la ribera del Riachuelo, afirmando que "ya sabían que el río hacía mal" (Patricia, 2015). Inmersos en esta experiencia (en muchos casos por décadas), los habitantes de estos barrios habían desarrollado "un conjunto de saberes prácticos — cuidados y prevenciones rutinarias - para lidiar con las dificultades presentadas por el medio ambiente en sus vidas cotidianas" (Scharager, 2017, p. 1160)

Dos de los delegados de la villa 21-24 remarcaban la gravedad de los efectos de la contaminación en la salud, particularmente de los niños, destacando el rol que la causa judicial había constituido como puntapié para que el Estado tuviera que llevar adelante acciones en ese sentido. Así lo relataba uno de ellos:

El tema del Riachuelo siempre nosotros, viste los que trabajábamos con chicos, esto que te estaba diciendo, siempre veíamos la problemática de los chicos, de la tos, de las enfermedades y siempre nos dimos cuenta de que era el sistema del Riachuelo. Después al darle comienzo al tema del censo y del camino de sirga hubo algunas instituciones que se preocuparon... O empezaron a trabajar en esto. (Marcelo, 2015)
Asimismo, otro de los referentes señalaba las falencias en el abordaje de las problemáticas y al destacar sus limitaciones, daba cuenta también de su conocimiento sobre la cuestión:

Acá cuando esto empezó venían móviles de canales... Lo único que hicieron fue lo de plomo en sangre, que nunca recibimos los resultados [se refiere al EISAAR, estudio realizado por el ACUMAR]. Pero acá hay tuberculosis, hay lombrices, los chicos tienen granos, problemas respiratorios, acá hay un montón de enfermedades por esto. (César, 2016)

Así, podríamos afirmar que los referentes consideraban las problemáticas ambientales, pero las enmarcaban más en un discurso vinculado con el acceso a la salud que en un activismo ambiental. A pesar de que este se encontraba en pleno crecimiento en el país (de manera más incipiente en el Área Metropolitana de Buenos Aires) y de la incorporación de estas problemáticas ambientales en la agenda pública (Gutiérrez, 2012), estas no llegaron a enraizarse con fuerza en los marcos de significados de los movimientos sociales urbanos, al menos en esta zona ( $\mathrm{y}$ aun cuando es un territorio atravesado por graves problemas de ese tipo).

Más allá de este conocimiento vinculado con la experiencia de vivir en un espacio contaminado, también vemos en los relatos de los referentes un desconocimiento y dudas acerca de sus causas, territarias 45 
como afirmaba Raquel, referente de la villa 21-24:

Hasta donde yo sé no. Porque mi casa está allá atrás nomás del Riachuelo. Igual lo que muchos dicen... Pero yo digo que hay muchos chicos que no viven al lado del Riachuelo y están enfermos del tema de bronco, de asma. Todos chicos, pero yo digo que no es. Para mi punto de vista no verdad, pero mucha gente dice que sí. (Raquel, 2015)

Otra de las delegadas del barrio se refería también al desconocimiento de las razones de las afecciones en la salud causadas por la contaminación y de las formas de tratarlas:

Acá hay mucha gente, yo nunca voy a decir que el que sabe menos que yo es ignorante, me parece que es falta de información, entonces yo digo, acá hay un montón de gente que, por falta de información, no sabe. (María, 2016)

Remarcamos también en este punto, retomando este fragmento, que es necesario diferenciar entre las nociones y saberes de los referentes, en permanente contacto con este caso y con el discurso ambiental a partir de la causa, de las de sus vecinos, que presentaron un desconocimiento aún mayor sobre su "experiencia tóxica".

De estos fragmentos y de lo observado podemos deducir que, los referentes sabían que habitaban un ambiente contaminado y lo denunciaron, pero que eligieron subordinarlo en sus repertorios de acción colectiva a otras demandas. Incluso, y sabiendo que algunas de las medidas tomadas no necesariamente mejoraban su "experiencia tóxica", negociaron y demandaron soluciones habitacionales y de infraestructura urbana como prioridad.

\section{Lenguaje del Estado y aprendizaje de derechos}

Te estoy hablando asi porque gracias a tanto luchar y preguntar y repreguntar estoy aprendiendo, pero hay muchas cosas a veces que no entiendo. Por eso

la Defensoría da gusto, porque les preguntás y ellos te explican todito, te muestran todito

(Bianca, 2016)

Los procesos de aprendizaje de derechos han sido señalados como uno de los efectos de la judicialización de los conflictos y de la política (Delamata et al., 2014). Por otra parte, ciertos trabajos (Manzano, 2008) abordaron la forma estratégica en que los sujetos utilizan el lenguaje del Estado para vincularse con los actores que intervienen en el diseño e implementación de políticas públicas. Podríamos decir que los análisis sobre la utilización de formas correctas de pedir al Estado (Pantaleón, 2004, citado en Olejarczyk, 2017) abordan también este tipo de fenómenos sociales, ocurridos en las 
relaciones entretejidas entre los receptores y aquellos que implementan las acciones estatales. Catalina Smulovitz (2008), por su parte, sostuvo que el surgimiento y difusión del lenguaje de derechos fue producto de su descubrimiento como herramienta para legitimar y dar entidad pública a demandas. Creemos que poner en diálogo ambos términos y sus implicancias, para tensionarlos y matizarlos, nos permite obtener una perspectiva más cabal de lo sucedido en los asentamientos de la ribera del Riachuelo. ¿ Existió una superposición de ambos procesos en los barrios de la cuenca?

En principio, podemos afirmar que los procesos de aprendizaje se relacionaron con múltiples dimensiones del conflicto. Por una parte, las experiencias organizativas fueron ámbitos de formación para los dirigentes, tanto para aquellos con mayor trayectoria como para quienes atravesaban por su primera experiencia de participación en estos espacios. También observamos la incorporación de formas de acción colectiva dentro del ámbito jurídico y la profundización del entendimiento del funcionamiento interno de ese campo. Así lo expresaba por ejemplo uno de los referentes del Campo Unamuno:

Siempre intentamos conocer más sobre la causa y sobre las distintas leyes que nos amparan y sobre desde qué lugar podemos avanzar, tenemos compañeros que llevan adelante eso, Alfonso por ejemplo es el que lo lleva adelante porque es el que más conocimiento tiene sobre todos los temas. A no todos nos tocan las mismas tareas digamos. (Martín, 2017)

Los nuevos saberes se articularon con sus acervos de conocimiento y experiencias previas. Los referentes retradujeron algunas de sus demandas en un discurso de derechos y accedieron al saber técnico jurídico, y puntualmente a los pormenores de la causa "Mendoza". Uno de los referentes de la villa 21-24 relataba ese proceso al ser entrevistado:

Al principio de este proceso a nosotros nos servían un montón, porque no sabíamos a dónde tocar puertas, a donde llegar solitos. No sabemos entregar papeles. Ahora dame un papel a mí, yo solo te lo llevo. Yo solo voy a llevar. Me abrieron los ojos. (Carlos, 2016)

Tuvieron en estos procesos un rol clave los abogados de la Defensa Pública y otros actores en los territorios, como relataba otro de los representantes del Cuerpo de delegados de la villa 21-24, al referirse a los abogados del Ministerio Público de la Defensa de la Ciudad:

Hay que reconocer que vinieron del cielo y les vamos a agradecer eternamente [...] Ellos nos ayudaron a comprender todo lo que es la problemática de lo que es la manda judicial, nos hicieron saber con 
certezas, como era la cuestión. Ellos nos ayudaron a pensar. Y bueno, nuestro eterno agradecimiento. (Manuel, 2015)

Más allá de estas cuestiones, que eran comunes a ambos barrios, observamos en la villa porteña una mayor utilización del discurso de derechos y del lenguaje de la justicia, que en el Campo Unamuno. En este último, las formas de presentar las demandas y de procesarlas eran en mayor medida similares a los discursos tradicionalmente políticos utilizados por los movimientos sociales urbanos de base territorial. A su vez, los representantes barriales de los dos barrios utilizaron el lenguaje de la ley para enmarcar sus demandas por la gran eficacia simbólica del derecho (Bourdieu, 2000) y también, por considerar que, en ese caso, constituía la forma más legítima de dirigirse a sus interlocutores estatales. Este framing o enmarcamiento legal (Delamata et al., 2014; Snow, 2004) supuso la organización de las prácticas y de los sucesos del conflicto dentro de esos términos o marcos de significación. Por ejemplo, en el siguiente fragmento el entrevistado destaca como argumento de validez de sus demandas su sustento en legislación específica:

Nosotros le planteamos de un modo muy tajante y sustentado en derechos, la Constitución lo declara, hay muchos tratados territarias 45 34 internacionales, que nuestro país aceptó, firmó, avaló, por lo tanto, eso también nos da derechos a nosotros. Derechos cívicos, derechos ciudadanos. (Claudio, 2015)

En relación al derecho al ambiente y el conocimiento de los problemas ambientales de los espacios que habitaban, también puede afirmarse que existió a la vez un aprendizaje y una utilización estratégica del mismo. Por una parte, a través de las reuniones con diversos actores estatales para negociar algunas de las políticas a implementar en sus barrios, la asistencia a audiencias públicas de la Corte Suprema de Justicia de la Nación y el intercambio con sus abogados, entre otros ámbitos, los referentes aprendieron acerca del riesgo ambiental al que estaban expuestos en mayor medida y desde la perspectiva de distintos saberes técnicos. Este conocimiento resultaba estratégico para posicionarse al negociar o confrontar con los actores del Poder Ejecutivo y Judicial. Por otra parte, aun cuando las demandas por el ambiente estuvieron casi ausentes en las entrevistas y espacios de organización barrial a los que se asistió, en las apariciones públicas de distintos delegados y referentes de barrios de la cuenca, las problemáticas ambientales constituían siempre el centro del conflicto. Podemos afirmar que esto resulta también de una elección estratégica, considerando que el derecho a la radicación y la urbanización de los asentamientos informales resulta una demanda mucho más cuestionada por la opinión pública que el acceso a un ambiente sano, aún más considerando 
el amparo judicial de sus reclamos. En este sentido, el discurso ambiental apareció como "la forma correcta de pedir" al Estado (Pantaleón, 2004, citado en Olejarczyk, 2017).

\section{Algunas reflexiones}

Los hallazgos de esta investigación permiten, por una parte, observar que las representaciones y experiencias en torno a la contaminación son múltiples, así como los saberes prácticos y las acciones tomadas en relación a esta. A pesar de un desconocimiento en términos técnicos o especializados de los efectos de vivir en un entorno tóxico, el estar atravesados cotidianamente por esa experiencia (hasta el punto de vivirlo en sus propios cuerpos) les da a los entrevistados una mirada clara acerca de sus consecuencias sobre su salud y vida cotidiana; además, de la relación que esto tiene con las desigualdades de las que son sujetos (sociales, económicas, etc.). Los problemas ambientales y las consecuencias sobre sus vidas aparecen como una dimensión más de la vulneración de sus derechos, pero no fueron formulados como reivindicaciones de sus acciones colectivas.

En segundo lugar, el presente trabajo permite destacar que, en las organizaciones barriales de la cuenca, en el marco de la causa judicial, primaron las demandas en torno a la vivienda y el hábitat por sobre las del derecho al ambiente. Aun cuando el Estado formuló el objeto de sus acciones y discursos en torno al ambiente, en la territorialización de estas políticas se negoció, confrontó y acordó en torno a otras demandas. Las fuertes tradiciones organizativas de los asentamientos informales del AMBA, centradas en los reclamos por tierra y vivienda, junto con el accionar errático, confuso y hasta contradictorio del Estado, no confluyeron en que el incipiente activismo ambiental observado por otros autores en la zona se generalizara entre estos sectores subordinados.

Más allá de estas cuestiones, puede afirmarse que los referentes atravesaron un proceso de aprendizaje de derechos y de saberes expertos en relación a su ambiente y en términos generales sobre el funcionamiento del campo jurídico. Así también, utilizaron de manera estratégica el discurso ambiental tanto en su vinculación con actores estatales como con los medios de comunicación, al tratarse del lenguaje del Estado y por ser una gramática con mayor legitimación social que sus demandas por la radicación y la urbanización de sus barrios.

Así, el artículo muestra la potencialidad de articular los campos de los estudios urbanos con los de la sociología ambiental, antropología y sociología política, en un contexto en el que las problemáticas ambientales vuelven a tener un lugar relevante en la agenda pública y política en la Argentina, e incluso a nivel global. En este marco resulta sustantiva la indagación en la dimensión ambiental de la desigualdad urbana y en las representaciones de 
los sectores populares acerca de su entorno. La regulación estatal es un factor central que, en la implementación de políticas urbano ambientales, incide en las representaciones sociales, las prácticas y la conformación de organización en estos territorios. A la vez que reproducen la confusión e incertidumbre acerca de los efectos de la contaminación; la existencia misma de estas políticas supone que el Estado le dé entidad (más allá de las limitaciones de sus acciones) y visibilidad a estas problemáticas. Esto resulta en una incorporación del discurso ambiental por parte de las organizaciones territoriales, lo que se constituye como una práctica estratégica y como el efecto de una serie de aprendizajes técnicos y de derechos que se articulan se con los extensos recorridos y trayectorias de lucha previa de estos sectores por el acceso a la vivienda y el suelo en el Área Metropolitana de Buenos Aires.

\section{Referencias}

Arcidiácono, P., \& Gamallo, G. (2013). Acerca de la justiciabilidad de los derechos sociales. Congreso 2013 de la Asociación de Estudios Latinoamericanos, Washington, D.C.

Auyero, J. (2013). Pacientes del Estado. EUDEBA.

Auyero, J., \& Swistun, D. (2007). Expuestos y confundidos. Un relato etnoterritarias 45 36 gráfico sobre sufrimiento ambiental. Íconos-Revista de Ciencias Sociales,
(28). https://doi.org/10.1714l/iconos.28.2007.216

Azuela, A., \& Mussetta, P. (2009). Algo más que el ambiente. Conflictos sociales en tres áreas naturales protegidas de México. Revista de Linguïstica Aplicada, 1(16), 191-215. http://ridaa.unq. edu.ar/handle/20.500.11807/1277

Benítez, J. (2018). El derecho a la ciudad como estructura de sentimiento. Formas pre-emergentes de significar la vivienda y el espacio urbano en la Ciudad Autónoma de Buenos Aires. Revista Cuaderno Urbano, 25(25), 31-49.

Bergallo, P. (2014). La causa "Mendoza": una experiencia de judicialización cooperativa sobre el derecho a la salud. En R. Gargarella (Comp.), Por una justicia dialógica: el Poder Judicial como promotor de la deliberación democrática (pp. 245-291). Siglo XXI.

Bourdieu, P. (1999). Meditaciones Pascalianas. Anagrama

Bourdieu, P. (2000). Elementos para una sociología del campo jurídico. En P. Bourdieu, \& G. Teubner, La fuerza del derecho (pp. 153-220). Uniandes; Siglo del Hombre.

Camelli, E. (2011). Las organizaciones políticas en las villas de Buenos Aires: entre la radicalidad sesentista y la fragmentación neoliberal. Revista de Estudios sobre Genocidio 5, 58-71.

Camelli, E. (2017). Los inicios de la organización política en las villas de la ciudad de Buenos Aires. URBANA: 
Revista Eletrônica do Centro Interdisciplinar de Estudos sobre a Cidade, 9(1), 182-203.

Cravino, M. C. (1998, octubre). Las organizaciones villeras en la Capital Federal entre 1989-1996. Entre la autonomía y el clientelismo (Vol. 10). Primer Congreso Virtual de Antropología y Arqueología, Buenos Aires.

Cravino, M. C. (2008): Vivir en la villa. Relatos, trayectorias y estrategias habitacionales. Universidad Nacional de General Sarmiento, UNGS.

Cravino, M. C., \& Fainstein, C. (2017). Disputas por el acceso al ambiente sano y la vivienda en la ribera del Riachuelo: derechos de los vecinos, acción de la Justicia y políticas públicas. En M. C. Cravino (Coord.), Detrás de los conflictos. Estudios sobre desigualdad urbana en la Región Metropolitana de Buenos Aires. UNGs, Los Polvorines.

Cravino, M. C., Del Rio, J. P., \& Duarte, J. I. (2008). Magnitud y crecimiento de las villas y asentamientos en el Área Metropolitana de Buenos Aires en los últimos 25 años [Conferencia no publicada]. XIV Encuentro de la Red Universitaria Latinoamericana de Cátedras de Vivienda, Buenos Aires, Argentina.

Delamata, G. (2013). Movimientos sociales, activismo constitucional y narrativa democrática en la Argentina contemporánea. Revista Sociologia, (32), 148-180.
Delamata, G., Sethman, A., \& Ricciardi, M. V. (2014). Más allá de los estrados. Activismo judicial y repertorios de acción villera en la ciudad de Buenos Aires. En L. Pautassi (Dir.), Marginaciones sociales en el Área Metropolitana de Buenos Aires. Acceso a la justicia, capacidades estatales y movilización legal (pp. 397-444). Biblos.

Fainstein, C. (2015). La relocalización de población del camino de sirga de la villa 21-24 ¿Erradicación o integración a la ciudad?: Representaciones y repertorios de acción colectiva en torno al reasentamiento. Quid 16: Revista del Área de Estudios Urbanos, (5), 255-283.

Fainstein, C. (2018). Las relocalizaciones masivas de población en los estudios urbanos. Aportes desde la experiencia de un asentamiento informal en la ribera del Riachuelo. Cuaderno urbano, 24(24), 93-116.

Fainstein, C. (2019). Politicas urbano-ambientales judicializadas. Organizaciones barriales y actores estatales en dos asentamientos del Área Metropolitana de Buenos Aires enmarcados en la causa "Mendoza" (2010-2018) (Tesis de Doctorado no Publicada). Facultad de Ciencias Sociales de la Universidad de Buenos Aires, Argentina.

Ferraudi Curto, M. C. (2014). Las fronteras cambiantes entre lo político y lo social: aportes etnográficos al debate en torno de "el 2001" en Argentina. 
Sociobistórica, (34). http://sedici. unlp.edu.ar/handle/10915/43959

Fiorito participa. (2013). Revista Corta la Bocha, (2), 9.

Gravano, A. (2003). Antropologia de lo barrial: estudios sobre producción simbólica de la vida urbana. Espacio Editorial Grimberg, M. (2009). Poder, políticas y vida cotidiana un estudio antropológico sobre protesta y resistencia social en el área metropolitana de Buenos Aires. Revista de Sociología e politica, 17(32), 83-94.

Gutiérrez, R. (2012). Federalismo y políticas ambientales en la Región Metropolitana de Buenos Aires, Argentina. Revista EURE, 38(114), 147-171.

Halbwachs, M. (2004). La memoria colectiva (Vol. 6). Prensas de la Universidad de Zaragoza.

Manzano, V. (2008). Etnografía de la gestión colectiva de políticas estatales en organizaciones de desocupados de La Matanza-Gran Buenos Aires. Runa, 28(1), 77-92. http://revistascientificas.filo.uba.ar/index.php/runa/article/view/1211

Melé, P. (2003). Introduction: Conflits, territoires et action publique. En P. Melé, C. Larrue, \& M. Rosemberg (Dirs.), Conflits et Territoires (pp. 1332). Maison des Sciences de L`Home; Presses Universitaires François Rabelais.

Melé, P. (2007, junio 7-8). Identifier un régime de territorialité réflexive.
Colloque: Territoires, territorialité, territorialisation: et après? Université Joseph Fourier, UMR Pacte Territoire; CNRS. Grenoble, Francia.

Merklen, D. (2010). Pobres ciudadanos: las clases populares en la era democrática. Argentina, 1983-2003. Gorla.

Merlinsky, G. (2014). Cartografias del conflicto ambiental en Argentina. CLACso; Ciccus.

Merlinsky, G. (2017). Cartografías del conflicto ambiental en Argentina. Notas teórico-metodológicas. Acta sociológica, (73), 221-246. http://dx.doi. org/10.1016/j.acso.2017.08.008

Merlinsky, M. G. (2013). Politica, derechosy justicia ambiental: el conflicto del Riachuelo. Fondo de Cultura Económica.

Moreno, L. (2013). La producción social del acuerdo: acción política y el lenguaje de los (des) acuerdos en un programa de construcción de viviendas sociales en la zona norte del Gran Buenos Aires. Revista Identidades, 5(8), 172-195.

Natalucci, A. (2011). Entre la movilización y la institucionalización: los dilemas de los movimientos sociales (Argentina, 2001-2010). Polis (Santiago), 10(28), 193-219.

Olejarczyk, R. (2017, septiembre). El tiempo de la (in)definición en las políticas de vivienda: de "tópicos del infortunio" y "saberes expertos". Trabajo Social Hoy, TSH, 82, 89-110. https:// doi.org/10.12960/TSH.2017.0017. 
Oszlak, O. (1991). Merecer la ciudad. Los pobres y el derecho al Espacio Urbano. Humanitas.

Pelli, V. S. (2004, diciembre). La casa bella, estética, identidad, poder y distorsión de metas en la vivienda social. Cuaderno Urbano, 4(4), 183-202. https:// doi.org/10.30972/crn.441047

Puga, M. (2014): El litigio estructural. Revista de Teoría del Derecho de la Universidad de Palermo, 41-82.

Scharager, A. (2017). Degradación ambiental en los márgenes urbanos. Los efectos sociales de una orden de relocalización en un barrio popular de Buenos Aires. Revista de Direito da Cidade, 9(3), 1147-1173.

Smulovitz, C. (2008, julio-septiembre / octubre-diciembre). La política por otros medios. Judicialización y movilización legal en Argentina. Desarrollo Económico-Revista de Ciencias Sociales, 48(190/191), 287-305.
Snitcofsky, V. L. (2018, julio). Un lugar en la Historia: orígenes, auge y declive de la Federación de Villas y Barrios de Emergencia. Encuentros Uruguayos, XI(1), 28-44. http:// www.encuru.fhuce.edu.uy/images/ revistas/numerol 1/02-Un-lugar-enla-Historia_-Snitcofsky-.pdf

Snow, D. (2004). Framing Processes, Ideo$\log y$, and Discursive Fields. En D. Snow, S. Soule, \& H. Kriesi (Eds.), The Blackwell Companion to Social Movements (Chapter 17, pp. 380-412). Publishing Ltd. Oxford.

Svampa, M. (2003). Entre la ruta y el barrio. La experiencia de las organizaciones piqueteras. Biblos.

Svampa, M. (2019). Las fronteras del neoextractivismo en América Latina: conflictos socioambientales, giro ecoterritorial y nuevas dependencias. CALAS. 